\title{
Assessing the Magnitude and Risk Factors Associated With Undiagnosed Hypertension in Rural Rwanda
}

\author{
Christian Mazimpaka ${ }^{1,3}$, Sabin Nsanzimana ${ }^{2}$, Jenae Logan ${ }^{3}$, Agnes Binagwaho ${ }^{3} \&$ Rex Wong $^{3}$ \\ ${ }^{1}$ Partners in Health, Rwanda \\ ${ }^{2}$ Ministry of Health, Rwanda \\ ${ }^{3}$ University of Global Health Equity, Rwanda \\ Correspondence: Christian Mazimpaka, Partners in Health, Rwanda. Tel: 250-783-545-391.
}

Received: January 12, 2019

Accepted: March 7, 2019

Online Published: March 11, 2019

doi:10.5430/jms.v10n2p3

URL: https://doi.org/10.5430/jms.v10n2p3

\begin{abstract}
Individuals living with hypertension are predisposed to higher risk of stroke, kidney diseases and heart failure. Approximately 9.4 million people worldwide die from complications related to hypertension every year. Hypertension is often known as the silent killer because many people do not develop any symptoms until they get very sick. Early screening is particularly important for better treatment outcomes yet it remains a challenge in many countries. Worldwide, approximately $50 \%$ of people are living with undiagnosed hypertension. In Rwanda, the rate of undiagnosed hypertension is unknown, and so are the associated risk factors in rural communities. A cross-sectional descriptive study was conducted to determine the rate and risk factors of undiagnosed hypertension among adults in a rural community in Rwanda.

The proportion of people having undiagnosed hypertension was found to be high. Out of 155 study participants, $41.9 \%$ had undiagnosed hypertension, with slightly more men having hypertension (52.3\%) than women (47.7\%). More than $98 \%$ of respondents either did not know or knew wrong information about hypertension, and only 3\% knew they should have regular checkups with physicians. Age $(\mathrm{p}=0.027)$ and alcohol consumption $(\mathrm{p}=0.014)$ were found to be statistically significantly associated with hypertension. Smoking and exercise were not found to be risk factors as most Rwandans living in the rural areas are physically active. Programs to promote hypertension awareness, encourage regular physical checkups, and reduce alcohol consumption are needed to improve diagnosis and control of hypertension in Rwanda. Community programs offering free regular blood pressure checks may also be helpful in identifying early hypertension. Larger scale studies of this kind should be conducted to understand whether results can be generalized to other areas of Rwanda
\end{abstract}

Keywords: undiagnosed hypertension, Rwanda, rural community, risk factors

\section{Introduction}

Globally, one billion individuals are living with high blood pressure, also known as hypertension, defined as having a blood pressure reading is higher than normal $(120 \mathrm{mmHg}$ for systolic and $80 \mathrm{mmHg}$ for diastolic pressure for adults) (WHO, 2017). In 2010, it was estimated that $46 \%$ of people aged 25 and above in Africa and 35\% in Western countries had hypertension (WHO, 2010). However, such prevalence could be higher in many low- and middle-income countries due to underdiagnosing and underreporting as a result of weaker health systems (WHO, 2014).

Worldwide, 51\% of stroke-related deaths (Gaciong, 2013), 46.9\% of cases of chronic kidney disease (Osafo et al., 2017), and 50\% of heart failures (Roger, 2013; WHO, 2014) are attributable to high systolic BP. Approximately 9.4 million deaths are due to complications of hypertension every year (Lim SS, Vos T, Flaxman AD, Danaei G, Shibuya K, Adair-Rohani H, 2012). In addition to its health effect, hypertension also has considerable economic impacts on individuals, their families, and societies. The total cost of treatment and lost productivity associated with non-communicable diseases, including hypertension, in low-income countries could be as high as 7 trillion USD between 2011 and 2025 (WHO, 2013). Such a huge financial burden mostly rests on patients and their families, especially in countries where financial protection from governments is limited and insurance systems are not well established (Kankeu, Saksena, Xu, \& Evans, 2013; Elliott, 2003). 
Hypertension is often known as a silent killer because many people do not develop any visible symptoms until they get very sick, causing worse treatment outcomes and higher treatment cost (Makridakis \& DiNicolantonio, 2014; Kankeu et al., 2013). In 2007, it was estimated that approximately $50 \%$ of people worldwide were living with undiagnosed hypertension (Chockalingam, 2007). Evidence has shown that early hypertension screening has been particularly effective in reducing mortality over the last three decades (World Health Organization, 2013; Arrieta, Woods, Qiao, \& Jay, 2014; Glynn et al., 2010; Wen et al., 2007; Hashmi et al., 2007; Hashmi et al., 2007; Puska, 2008; Kankeu et al., 2013). Nonetheless, early screening of hypertension remains a challenge in many countries (Khatib et al., 2014; WHO, 2000).

In Rwanda, two cross sectional studies were conducted in two urban settings and found that $36 \%$ to $38.3 \%$ of participants had hypertension, but only 3\% to $8 \%$ were aware of their hypertensive status (Banyangiriki \& Phillips, 2013; Umwangange, 2016), indicating the severity of undiagnosed hypertension in Rwanda. However, both studies were conducted in urban communities in Rwanda. Accordingly, this study was conducted to assess the rate of undiagnosed hypertension and the associated risk factors in a rural community.

\section{Method}

\subsection{Setting}

This study was conducted in a rural community in Rulindo district, Rwanda. The district has a total population of 287,681 , of which $97 \%$ of them live in rural areas (NISR, 2012)

\subsection{Study Design and Sample}

A cross-sectional study was conducted to determine the rate of and risk factors for undiagnosed hypertension among adults. Individuals who were 18 years or older were randomly selected from the community to participate in a survey and hypertension screening. Individuals who were previously diagnosed with hypertension were excluded from this study.

\subsection{Measures and Data Collection}

The key measure of this study was the prevalence of hypertension. A participant was classified as hypertensive when his/her systolic blood pressure was equal to or above $140 \mathrm{MmHg}$ and/or diastolic blood pressure was equal to or above $90 \mathrm{MmHg}$. Some basic demographic information and potential risk factors were also collected. Participants were invited by data collectors to participate in the study at the sites where the community held their monthly community services in March 2017. After data collectors explained the purpose and procedures of the study, they obtained informed consent from each participant. A private room was set up at the study site to provide privacy for the participants. Data collected included basic demographics; habits related to exercise, smoking and alcohol consumption; and knowledge about the definition of hypertension and optimal frequency of seeing a physician for checkups. The blood pressure, weight, and height of the participants were also measured. The interviews/examinations were conducted in Kinyarwanda (the local language). The information collected was recorded in a data collection form. The data collection form was designed in English and was translated to Kinyarwanda and back translated by two independent translators to ensure consistency. Participants' names were not collected to ensure that participants' privacy was protected.

\subsection{Data Analysis}

Descriptive statistics were used to summarize the characteristics of the sample. Chi-square tests were used to analyze the association of all variables with hypertension. All statistical analyses were conducted using SPSS v.21, with the significance level set at 0.05 .

\section{Results}

A total of 155 respondents met the inclusion and exclusion criteria. Among them, 85 (54.8\%) were females and 70 $(45.2 \%)$ were males. The average age of the respondents was 42.8 years ( $\mathrm{SD} \pm 12.3$ ). The majority of the participants had only obtained the primary level of education $(114,73.5 \%)$. More than $83 \%$ were in socio-economic categories 2 and $3,76.1 \%$ did not perform any physical exercise outside their work, $16.8 \%$ were smokers, $67.1 \%$ consumed one to three bottles of alcohol per day, and $80.6 \%$ were within normal BMI range (table 1). Out of all participants, 152 (98.1\%) did not know what hypertension was and 151 (97.4\%) did not know how often they should see a physician for a checkup (Table 1). The result showed 65 out of the 155 participants were found to have hypertension, translating to $41.9 \%$ prevalence (Table 1 ). 
Table 1. Table summarizing the characteristics of the sample

\begin{tabular}{|c|c|c|}
\hline Variable & & $\mathrm{n}(\%)$ \\
\hline Sample (N) & & 155 \\
\hline \multirow[t]{4}{*}{ Age (year) } & Mean (SD) & $42.8( \pm 12.3)$ \\
\hline & $<35$ & $41(26.5 \%)$ \\
\hline & $35-50$ & $73(47.1 \%)$ \\
\hline & $>50$ & $40(25.8 \%)$ \\
\hline \multirow[t]{2}{*}{ Sex } & Male & $70(45.2 \%)$ \\
\hline & Female & $85(54.8 \%)$ \\
\hline \multirow[t]{4}{*}{ Education } & None & $30(19.4 \%)$ \\
\hline & Primary & $114(73.5 \%)$ \\
\hline & Secondary & $9(5.8 \%)$ \\
\hline & College or above & $2(1.3 \%)$ \\
\hline \multirow[t]{4}{*}{ Socioeconomic class } & 1 (poor) & $23(14.8 \%)$ \\
\hline & 2 & $68(43.9 \%)$ \\
\hline & 3 & $61(39.4 \%)$ \\
\hline & 4 (rich) & $2(1.3 \%)$ \\
\hline \multirow[t]{3}{*}{ Exercise } & None & $118(76.1 \%)$ \\
\hline & $<3$ times per week & $25(16.1 \%)$ \\
\hline & 3 times or more per week & $12(7.7 \%)$ \\
\hline \multirow[t]{3}{*}{ Smoking } & None & $129(83.2 \%)$ \\
\hline & $<10$ cigarettes a day & $23(14.8 \%)$ \\
\hline & 10 or more cigarettes a day & $3(1.9 \%)$ \\
\hline \multirow[t]{3}{*}{ Alcohol } & None & $47(30.3 \%)$ \\
\hline & $1-3$ bottles a day & $104(67.1 \%)$ \\
\hline & $>3$ bottles a day & $4(2.6 \%)$ \\
\hline \multirow[t]{2}{*}{ Knowledge on HT } & Not knowing or incorrect & $152(98.1 \%)$ \\
\hline & Correct & $3(1.9 \%)$ \\
\hline \multirow[t]{2}{*}{ Knowing how often for physical } & No & $151(97.4 \%)$ \\
\hline & Yes & $4(2.6 \%)$ \\
\hline \multirow[t]{4}{*}{ BMI } & Underweight $(<18.5)$ & $10(6.5 \%)$ \\
\hline & Normal (18.5 - 24.9) & $125(80.6 \%)$ \\
\hline & Overweight (25-29.9) & $17(11.0 \%)$ \\
\hline & Obese (30 or more) & $3(1.9 \%)$ \\
\hline \multirow[t]{2}{*}{ HT prevalence } & No HT & $90(58.1 \%)$ \\
\hline & HT & $65(41.9 \%)$ \\
\hline
\end{tabular}

In the bivariate analysis conducted to identify the risk factors associated with hypertension, age $(\mathrm{p}=0.027)$ and alcohol consumption $(\mathrm{p}=0.014)$ were found to be statistically significant (Table 2). Gender, education level, socioeconomic class, frequency of exercise, smoking status, BMI and knowledge were not statistically significant at $\mathrm{p}=0.05$. 
Table 2. Results of bivariate analysis to hypertension

\begin{tabular}{|c|c|c|c|}
\hline Variables & & HT & P-value \\
\hline \multirow[t]{3}{*}{ Age (year) } & $<35$ & $16(24.6 \%)$ & \\
\hline & $35-50$ & $25(38.5 \%)$ & $0.027 *$ \\
\hline & $>50$ & $24(36.9 \%)$ & \\
\hline \multirow[t]{2}{*}{ Sex } & Male & $34(52.3 \%)$ & \\
\hline & Female & $31(47.7 \%)$ & 0.143 \\
\hline \multirow[t]{4}{*}{ Education } & None & $16(24.6 \%)$ & 0.366 \\
\hline & Primary & $43(66.2 \%)$ & \\
\hline & Secondary & $5(7.7 \%)$ & \\
\hline & College or above & $1(1.5 \%)$ & \\
\hline \multirow[t]{4}{*}{ Socioeconomic class } & 1 (poor) & $9(13.8 \%)$ & \\
\hline & 2 & $25(38.5 \%)$ & 0.536 \\
\hline & 3 & $30(46.2 \%)$ & \\
\hline & 4 (rich) & $1(1.5 \%)$ & \\
\hline \multirow[t]{3}{*}{ Exercise } & None & $52(80.0 \%)$ & \\
\hline & $<3$ times per week & $9(13.8 \%)$ & 0.623 \\
\hline & 3 times or more per week & $4(6.2 \%)$ & \\
\hline \multirow[t]{3}{*}{ Smoking } & None & $50(76.9 \%)$ & \\
\hline & $<10$ cigarettes a day & $14(21.5 \%)$ & 0.135 \\
\hline & 10 or more cigarettes a day & $1(1.5 \%)$ & \\
\hline \multirow[t]{3}{*}{ Alcohol } & None & $12(18.5 \%)$ & \\
\hline & $1-3$ bottles a day & $50(76.9 \%)$ & $0.014 *$ \\
\hline & $>3$ bottles a day & $3(4.6 \%)$ & \\
\hline \multirow[t]{2}{*}{ Knowledge on HT } & Not knowing or incorrect & $63(96.9 \%)$ & 0.572 \\
\hline & Correct & $2(3.1 \%)$ & \\
\hline \multirow[t]{2}{*}{ Knowing how often for physical } & No & $64(98.5 \%)$ & 0.640 \\
\hline & Yes & $1(1.5 \%)$ & \\
\hline \multirow[t]{4}{*}{ BMI } & Underweight $(<18.5)$ & $5(7.7 \%)$ & 0.706 \\
\hline & Normal (18.5 - 24.9) & $50(76.9 \%)$ & \\
\hline & Overweight (25-29.9) & $8(12.3 \%)$ & \\
\hline & Obese (30 or more) & $2(3.1 \%)$ & \\
\hline
\end{tabular}

* significant at $\mathrm{p}=0.05$

\section{Discussion}

Our study found that $41.9 \%$ of the adults residing in rural Rulindo district were hypertensive without previously being diagnosed. The prevalence was slightly higher than that found by the two studies previously conducted in Rwanda, in which data was collected in mixed settings that included both rural and urban populations (Banyangiriki \& Phillips, 2013; Umwangange, 2016). Many studies have shown that men are more prone to having hypertension (Cutler et al. 2008; Vitale, Mendelsohn, Rosano, 2009; Sandberg and Ji 2012; Vitale et al. 2010), and our study also found that more men had hypertension, although the difference was not statistically significant. The prevalence of hypertension among older age groups were statistically significantly higher, which is consistent with the general physiological understanding of hypertension - the blood vessel walls become less elastic as we age (Franklin, Jacobs, Wong, L'italien, \& Lapuerta, 2001; Anderson, 1999).

The levels of exercise, alcohol consumption, and smoking habits of our sample resembled those of the general Rwanda population (MOH/RBC, 2015). Since smoking is not common among Rwandans and only a very small proportion of our sample were smokers, it is reasonable to expect no significant association could be detected 
between smoking and hypertension in our study despite the fact that smoking is a common risk factor for hypertension (Niskanen, et al, 2004).

Exercise has been well established to be a protective factor against hypertension for decades (Blair, Goodyear, Gibbons, \& Cooper, 1984; Hayashi, Tsumura, Suematsu, Okada, Fujii, \& Endo, 1999; Pereira, et al, 1999; Haskell, et al, 2007; Hu, Barengo, Tuomilehto, Lakka, Nissinen, Jousilahti, 2004). Our study did not find significant association. However, the results must be interpreted with care. For most people living in rural areas in Rwanda, physical activities are part of their daily lives, from working in the farm to fetching water, from delivering goods to markets to walking to workplaces. While many respondents many not consider these activities as "exercise" when responding to our questionnaires, they could be indeed physically active - supported by the evidence that most respondents also fell within the normal BMI range.

While most Rwandans do not smoke cigarettes, drinking alcohol is common; nearly $70 \%$ of our respondents reported that they consumed some alcohol on regular basis. According to an unofficial report by Helicopter View, a private business organization in Europe, Rwanda ranked 4th among the countries that consume the most alcohol in Africa, behind only Nigeria, Uganda and Kenya (Helicopter View, 2017). Decades of epidemiologic evidences have established that alcohol consumption a risk factor for hypertension (Sesso, Cook, Buring, Manson, \& Gaziano, 2008; Klatsky, 1996; Beilin \& Puddey, 2006; Taylor, et al, 2009; Shang et al., 2016) and our results showed the same. Effective policies or interventions for hypertension in Rwanda must not ignore alcohol consumption.

Having basic knowledge about hypertension is important for blood pressure control (El-hay \& Mezayen, 2015; Hashmi et al., 2007; Egan, Zhao, Axon, 2010; Guo, He, Zhang, Walton, 2012). This study found that more than 98\% of respondents either did not know what hypertension was or had incorrect information about hypertension. In addition, only 3\% knew they should have regular checkups with physicians. Despite the current Rwandan MOH policy encouraging citizens to have yearly routine checkups, which are covered by the community-based health insurance (Rwanda, 2014), most study participants were not aware of the policy or coverage. The low uptake of regular physical checkups and the absence of signs and symptoms of early stage of hypertension both contribute to a high percentage of hypertension cases left undiagnosed in Rwanda. Interventions to raise awareness of hypertension and to promote regular physical checkups are necessary. Community programs that provide free regular blood pressure checks may also be helpful in diagnosing hypertension early.

\section{Conclusion}

Our study was the first in Rwanda to measure the prevalence of undiagnosed hypertension in a rural setting. Although the sample size was relatively small, our findings are comparable to those of other studies carried out in Rwanda. Nonetheless, a larger scale study of this kind should be conducted to fully understand the epidemiology of undiagnosed hypertension in Rwanda. Hypertension-related programs should focus on raising awareness, reducing alcohol consumption, and encouraging regular physical checkups. Services providing regular free blood pressure checks in the community would also promote earlier diagnosis.

\section{Acknowledgement}

The authors want to thank Dominique Ruleau and Isabel Fulcher for their assistance in this project; also Chance Mumukunde, Josee Mukanoheli, Gaudiose Ashimwe, Julienne Mukandagijimana, and Dieudone Dukundane for their support in data collection.

\section{References}

Anderson, G. H. (1999). Effect of age on hypertension: analysis of over 4,800 referred hypertensive patients. Saudi Journal of Kidney Diseases and Transplantation, 10(3), 286.

Arrieta, A., Woods, J. R., Qiao, N., \& Jay, S. J. (2014). Cost-benefit analysis of home blood pressure monitoring in hypertension diagnosis and treatment: An insurer perspective. Hypertension, 64(4), 891-896. https://doi.org/10.1161/HYPERTENSIONAHA.114.03780

Banyangiriki, J., \& Phillips, J. (2013). Prevalence of hypertension among working adults in Rwanda. Iranian Journal of Public Health, 42(8), 925-926.

Beilin, L. J., \& Puddey, I. B. (2006). Alcohol and hypertension: an update. Hypertension, 47(6), 1035-1038. https://doi.org/10.1161/01.HYP.0000218586.21932.3c

Blair, S. N., Goodyear, N. N., Gibbons, L. W., \& Cooper, K. H. (1984). Physical fitness and incidence of hypertension in healthy normotensive men and women. Jama, 252(4), 487-490. https://doi.org/10.1001/jama.1984.03350040017014 
Cutler, J. A., Sorlie, P. D., Wolz, M., Thom, T., Fields, L. E., \& Roccella, E. J. (2008). Trends in hypertension prevalence, awareness, treatment, and control rates in United States adults between 1988-1994 and 1999-2004. Hypertension, 52(5), 818-827. https://doi.org/10.1161/HYPERTENSIONAHA.108.113357

Egan, B. M., Zhao, Y., \& Axon, R. N. (2010). US trends in prevalence, awareness, treatment, and control of hypertension, 1988-2008. Jama, 303(20), 2043-2050. https://doi.org/10.1001/jama.2010.650

El-hay, S. A. A., \& Mezayen, S. E. E. (2015). Knowledge and Perceptions Related to Hypertension, Lifestyle Behavior Modifications and Challenges That Facing Hypertensive Patients. Journal of Nursing and Health Science, 4(6), 15-26.

Elliott, W. J. (2003). The economic impact of hypertension. Journal of Clinical Hypertension (Greenwich, Conn.), 5(3 Suppl 2), 3-13. https://doi.org/10.1111/j.1524-6175.2003.02463.x

Franklin, S. S., Jacobs, M. J., Wong, N. D., L'italien, G. J., \& Lapuerta, P. (2001). Predominance of isolated systolic hypertension among middle-aged and elderly US hypertensives: analysis based on National Health and Nutrition Examination Survey (NHANES) III. Hypertension, 37(3), 869-874. https://doi.org/10.1161/01.HYP.37.3.869

Gaciong, Z., Sinski, M., \& Lewandowski, J. (2013). Blood pressure control and primary prevention of stroke: summary of the recent clinical trial data and meta-analyses. Curr Hypertens Rep, 15, 559-74. https://doi.org/10.1007/s11906-013-0401-0

Glynn, L. G., Murphy, A. W., Smith, S. M., Schroeder, K., Fahey, T., Glynn, L. G., ... Fahey, T. (2010). Interventions used to improve control of blood pressure in patients with hypertension (Review) Interventions used to improve control of blood pressure in patients with hypertension. Public Health, (3), 3-6.

Guo, F., He, D., Zhang, W., \& Walton, R. G. (2012). Trends in prevalence, awareness, management, and control of hypertension among United States adults, 1999 to 2010. J Am Coll Cardiol, 60(7), 599-606. https://doi.org/10.1016/j.jacc.2012.04.026

Hashmi, S. K., Afridi, M. B., Abbas, K., Sajwani, R. A., Saleheen, D., Frossard, P. M., \& Ahmad, U. (2007). Factors associated with adherence to anti-hypertensive treatment in Pakistan. PLoS ONE, 2(3). https://doi.org/10.1371/journal.pone.0000280

Haskell, W. L., Lee, I., Pate, R. R., Powell, K. E., Blair, S. N., Franklin, B. A., ... Bauman, A. (2007). Physical activity and public health: updated recommendation for adults from the American College of Sports Medicine and the American Heart Association. Med Sci Sports Exerc, 39(8), 1423-1434. https://doi.org/10.1249/mss.0b013e3180616b27

Hayashi, T., Tsumura, K., Suematsu, C., Okada, K., Fujii, S., \& Endo, G. (1999). Walking to work and the risk for hypertension in men: the Osaka Health Survey. Annals of Internal Medicine, 131(1), 21-26. https://doi.org/10.7326/0003-4819-131-1-199907060-00005

Helicopter View. (2017). Top-10 Alcohol-drinking countries in Africa. Retrieved November 2018, from http://helicopter-view.com/blog/top-10-alcohol-drinking-countries-in-africa1

Hu, G., Barengo, N. C., Tuomilehto, J., Lakka, T. A., Nissinen, A., \& Jousilahti, P. (2004). Relationship of physical activity and body mass index to the risk of hypertension: a prospective study in Finland. Hypertension, 43(1), 25-30. https://doi.org/10.1161/01.HYP.0000107400.72456.19

Kankeu, H. T., Saksena, P., Xu, K., \& Evans, D. B. (2013). The financial burden from non-communicable diseases in low- and middle-income countries: a literature review. Health Research Policy and Systems, 11(1), 31. https://doi.org/10.1186/1478-4505-11-31

Khatib, R., Schwalm, J. D., Yusuf, S., Haynes, R. B., McKee, M., Khan, M., \& Nieuwlaat, R. (2014). Patient and healthcare provider barriers to hypertension awareness, treatment and follow up: A systematic review and meta-analysis of qualitative and quantitative studies. PLoS ONE, 9(1), 1-12. https://doi.org/10.1371/journal.pone.0084238

Klatsky, A. L. (1996). Alcohol and hypertension. Clinica Chimica Acta, 246(1-2), 91-105. https://doi.org/10.1016/0009-8981(96)06230-4

Lim, S. S., Vos, T., Flaxman, A. D., Danaei, G., Shibuya, K., Adair-Rohani, H., et al. (2012). A comparative risk assessment of burden of disease and injury attributable to 67 risk factors and risk factor clusters in 21 regions, 1990-2010: a systematic analysis for the Global Burden of Disease Study 2010. Lancet, 15(380), 2224-2260. 
https://doi.org/10.1016/S0140-6736(12)61766-8

Makridakis, S., \& DiNicolantonio, J. J. (2014). Hypertension: empirical evidence and implications in 2014. Open Heart, 1(1), e000048. https://doi.org/10.1136/openhrt-2014-000048

Ministry of Health Rwanda. (2015). Non Communicable Diseases Policy.

MOH/RBC. (2015). Rwanda Non-Communicable Diseases Risk Factors Report.

Niskanen, L., Laaksonen, D. E., Nyyssönen, K., Punnonen, K., Valkonen, V.-P., Fuentes, R., ... Salonen, J. T. (2004). Inflammation, abdominal obesity, and smoking as predictors of hypertension. Hypertension, 44(6), 859-865. https://doi.org/10.1161/01.HYP.0000146691.51307.84

Osafo, C., Mate-Kole, M., Affram, K., \& Adu, D. (2011). Prevalence of chronic kidney disease in hypertensive patients in Ghana. Renal Failure, 33(4), 388-392. https://doi.org/10.3109/0886022X.2011.565140

Pereira, M. A., Folsom, A. R., McGovern, P. G., Carpenter, M., Arnett, D. K., Liao, D., ... \& Atherosclerosis Risk in Communities Study Investigators. (1999). Physical activity and incident hypertension in black and white adults: the Atherosclerosis Risk in Communities Study. Preventive Medicine, 28(3), 304-312. https://doi.org/10.1006/pmed.1998.0431

Puska, P. (2008, May). The North Karelia Project: 30 years successfully preventing chronic diseases. Diabetes Voice, $53,26-29$.

Roger, V. L. (2013). Epidemiology of heart failure. Circulation Research, 113(6), 646-659. https://doi.org/10.1161/CIRCRESAHA.113.300268

Sandberg, K., \& Ji, H. (2012). Sex differences in primary hypertension. Biol Sex Differ, 3(1), 7. https://doi.org/10.1186/2042-6410-3-7

Sesso, H. D., Cook, N. R., Buring, J. E., Manson, J. E., \& Gaziano, J. M. (2008). Alcohol consumption and the risk of hypertension in women and men. Hypertension, 51(4), 1080-1087. https://doi.org/10.1161/HYPERTENSIONAHA.107.104968

Shang, S., Li, P., Deng, M., Jiang, Y., Chen, C., \& Qu, Q. (2016). The Age-Dependent Relationship between Blood Pressure and Cognitive Impairment: A Cross-Sectional Study in a Rural Area of. PLoS ONE, 989, 1-18. https://doi.org/10.1371/journal.pone.0159485

Taylor, B., Irving, H. M., Baliunas, D., Roerecke, M., Patra, J., Mohapatra, S., \& Rehm, J. (2009). Alcohol and hypertension: gender differences in dose-response relationships determined through systematic review and meta-analysis. Addiction, 104(12), 1981-1990. https://doi.org/10.1111/j.1360-0443.2009.02694.x

Umwangange, M. L. (2016). Screening for Hypertension in People Aged 50 Years and Older in Byumba Sector: A Community-Based Approach. OALib, 3(12), 1-10. https://doi.org/10.4236/oalib.1103213

Vitale, C., Fini, M., Speziale, G., \& Chierchia, S. ((2010). Gender differences in the cardiovascular effects of sex hormones. Fundam Clin Pharmacol, 24(6), 675-685. https://doi.org/10.1111/j.1472-8206.2010.00817.x

Vitale, C., Mendelsohn, M. E., \& Rosano, G. M. C. (2009). Gender differences in the cardiovascular effect of sex hormones. Nat Rev Cardiol, 6(8), 532-542. https://doi.org/10.1038/nrcardio.2009.105

Wen, B., Lampe, J. N., Roberts, A. G., Atkins, W. M., Rodrigues, A. D., \& Nelson, S. D. (2007, October). NIH Public Access, 454(1), 42-54.

WHO. (2010). Global status report on noncommunicable diseases.

WHO. (2013a). Development of an updated Action Plan for the Global Strategy for the Prevention and Control of Noncommunicable Diseases covering the period 2013 to 2020.

WHO. (2013b). A global brief on hypertension: silent killer, global public health crisis. World Health Day 2013.

WHO. (2014). Global status report on noncommunicable diseases 2014. World Health, 176.

WHO. (2017). Hypertension. Retrieved January 16, 2017, from http://www.who.int/cardiovascular_diseases/publications/global_brief_hypertension/en/ 